\title{
O XADREZ PEDAGÓGICO COMO POTENCIALIZADOR DE ENSINO APRENDIZAGEM DOS CONTEÚDOS MATEMÁTICOS NO ENSINO FUNDAMENTAL
}

\author{
Aparecida Dias de Macedo ${ }^{1}$ \\ Ariane Delprete Faria ${ }^{2}$
}

\section{RESUMO}

O presente trabalho visa investigar a relação entre o xadrez pedagógico e os conteúdos matemáticos, procurando avaliar as possibilidades do uso do jogo de xadrez como recurso didático em aulas de matemática. Averiguou-se que a articulação entre o jogo de xadrez e a educação matemática de alunos do sexto ao nono ano do ensino fundamental na EMEF Sebastião Costa, no município de Muniz Freire, no Estado do Espírito Santo, foi de total relevância na promoção e simulação de situações-problema, fomentando o desenvolvimento cognitivo dos alunos. A pesquisa, de caráter qualitativo, analisou os conteúdos desenvolvidos, tais como plano cartesiano, geometria e frações. Usando o jogo de xadrez para o ensino destes conteúdos, verificamos uma melhora significativa no desempenho da disciplina de matemática, bem como o maior interesse e dedicação à matéria por parte dos alunos.

Palavras-chave: Xadrez pedagógico. Recurso didático. Conteúdos matemáticos.

\section{ABSTRACT}

The present work aims to investigate the relationship between pedagogical chess and mathematical contents, trying to evaluate the possibilities of using the game of chess as a didactic resource in mathematics classes. It was verified that the articulation between the chess game and the mathematical education of students from the sixth to the ninth year of elementary school at the EMEF Sebastião Costa, in the municipality of Muniz Freire, in the State of Espírito Santo, was of total relevance in the promotion and simulation of problem situations, fostering students' cognitive development. The research, of qualitative character, analyzed the developed contents, such as cartesian plan, geometry and fractions. Using the game of chess to teach this content, we see a significant improvement in the performance of these

\footnotetext{
${ }^{1}$ Graduada em Licenciatura Plena em Matemática pela Faculdade de Filosofia, Ciências e Letras de Alegre_ES, Licenciatura Plena em Geografia pela Universidade Metropolitana de Santos, especialista Lato sensu em Educação Especial e Matemática pela Faculdades Integradas de Jacarepaguá, especialista Lato sensu em Gestão Escolar Integradora pela Universidade Castelo Branco, aluna do curso de Mestrado Scricto Sensu pelo Facultad Interamericana de Cièncias Sociales- FICS, atua como professora na rede municipal de Muniz FreireES.

${ }^{2}$ Graduada em Licenciatura Plena em Ciências Biológicas pela Faculdade de Filosofia, Ciências e Letras de Alegre, especialista Lato sensu em Educação Ambiental e Recursos Naturais pela Faculdade de Ciências e Letras de Alegre, especialista em Ciências Biológicas pela Faculdade do Noroeste de Minas (FINOM), aluna do curso de Mestrado Scricto Sensu pelo Institute of Tecnology Education e Health, atua como professora na rede municipal de Muniz Freire-ES.
} 
mathematics disciplines, as well as the greater interest and dedication to the subject by the students.

Key words: Pedagogical chess. Didactic resource. Mathematical contents.

\section{RESUMEN}

El presente trabajo busca investigar la relación entre el ajedrez pedagógico y los contenidos matemáticos, buscando evaluar las posibilidades del uso del juego de ajedrez como recurso didáctico en clases de matemáticas. Se verificó que la articulación entre el juego de ajedrez y la educación matemática de alumnos del sexto al noveno año de la enseñanza fundamental en la EMEF Sebastião Costa, en el municipio de Muniz Freire, en el Estado de Espírito Santo, fue de total relevancia en la promoción y simulación de situaciones-problema, fomentando el desarrollo cognitivo de los alumnos. La investigación, de carácter cualitativo, analizó los contenidos desarrollados, tales como plano cartesiano, geometría y fracciones. Utilizando el juego de ajedrez para la enseñanza de estos contenidos, verificamos una mejora significativa en el desempeño de esas disciplinas de las matemáticas, así como el mayor interés y dedicación a la materia por parte de los alumnos.

Palabras clave: Ajedrez pedagógico. Recurso didáctico. Contenidos matemáticos.

\section{INTRODUÇÃO}

O xadrez é claramente reconhecido pela sua contribuição na sociedade nas áreas sociais e científicas. Na discussão pedagógica é, entretanto, contestável. Há uma desconfiança corriqueira sobre a real efetividade deste jogo como ferramenta importante do ensino aprendizagem dos alunos, independente da matéria.

O problema de pesquisa tende a levar a um novo patamar uma antiga discussão sobre a efetividade de jogos matemáticos e o quanto estes agregam no conteúdo matemático didático. O fato é que o jogo de xadrez lida com raciocínio lógico, cognição, habilidades motoras, respeito às regras, dentre outros efetivos habilidades imprescindíveis para a matéria de matemática.

A questão é: será que o jogo de xadrez influencia no desempenho do aluno na matéria, em si? O jogo realmente desenvolve algumas dessas habilidades para alunos que outrora não a possuíam? E, no caso de alunos que já possuem tais habilidades, o xadrez pedagógico é uma ferramenta que tem o "poder" de potencializá-las? 
Jogos pedagógicos não se tratam apenas de ocupar o tempo dos alunos com atividades simples, mas sim de desenvolver habilidades com uma profundidade de aprendizagem mais complexa. Jogos exigem o empenho do usuário; a inteligência e o senso de criatividade para se sobressair em uma situação de dificuldade; a resistência para longos períodos de concentração; e a condução para que ele sempre faça as melhores escolhas. E não é para isso que preparamos os alunos de nossas escolas para o futuro?

Este trabalho pôde desmistificar a ideia de que o jogo de xadrez é importante, mas que não traz uma real efetividade no ensino aprendizagem dos alunos. A pesquisa e discussão dos resultados certificaram que a aplicação do xadrez pedagógico, como ferramenta de ensino aprendizagem dos alunos, realmente influencia diretamente no desempenho de uma disciplina escolar: a matemática.

É importante ressaltar que, em muitos países, assim como no Brasil, o jogo de xadrez já é inserido dentro do cronograma das escolas, proporcionando um alto índice de aprendizagem. Ele é utilizado como elemento estruturador do tempo livre dos docentes no âmbito escolar, influenciando no convívio em sociedade, proporcionando prazer em seus estudos e prática.

Como professora, acompanho e convivo diariamente com a maior dificuldade entre os alunos da Escola Municipal Sebastião Costa: a interpretação. A interpretação - ou sua ausência, neste caso - está presente em cada enunciado, em cada situação problema, em cada questão lógica que necessita de uma explicação. Este é um problema real, recorrente, mas que, por experiência própria, tem solução.

O xadrez é um jogo de origem milenar, conhecido no mundo inteiro, e que é incentivado nesta escola, a fim não somente de utilizá-lo como lazer, mas como uma atividade que coloca literalmente em "xeque" o problema da interpretação e outras dificuldades dos educandos.

Devido à falta de atenção, concentração e raciocínio, o xadrez compete como uma solução para estes tipos de comportamento. Durante vários anos, pude acompanhar e comprovar pessoalmente a evolução socioeducativa de centenas de alunos que, ao participarem dos jogos de xadrez, conseguiram obter melhores desempenhos em relação às notas da matéria, além de uma notável melhora em seus comportamentos pessoais. 
Trata-se do chamado xadrez pedagógico, no qual o xadrez tem por finalidade melhorar o desempenho escolar, desenvolvendo inclusive habilidades que combatem as maiores dificuldades dos alunos, como a interpretação, citada anteriormente.

Dessa forma, este trabalho tem como justificativa uma necessidade pessoal e profissional de comprovar - desta vez com embasamento mais profundos, teóricos e práticos - que a aplicação do jogo de xadrez pedagógico nos conteúdos matemáticos pode potencializar o processo de ensino aprendizagem dos educandos das séries de ensino fundamental.

\section{O XADREZ NO CAMPO DA EDUCAÇÃO E DA PESQUISA}

O xadrez é visto como um jogo complexo, repleto de características, regras e implicações, mas também de benefícios, dentre eles a autoconfiança, senso de criatividade e observação, além do avanço cognitivo e cultural (GIACHINI, 2011). Dessa forma, para Silva (2009), o xadrez incita a mente, instiga a atenção e desenvolve a formação do jogador, como pessoa.

O xadrez, para Angélico e Porfírio (2010) é intrigante. Os autores também entram em consenso sobre a importância deste jogo, no qual, em suas pesquisas, levantaram alguns testemunhos pessoais do que seria o xadrez para jogadores fascinados. Dentre as respostas, o primeiro, que era comerciante, revelou que o jogo o fez perceber a grande importância do planejamento, afinal o xadrez não era passível do elemento sorte, e sem planejamento não haveria como obter a vitória em um jogo, assim como era no mercado em que ele atuava. $O$ segundo, que era músico, descreveu o jogo como um próprio reflexo de sua vida: coordenava a razão como parte de sua vocação. O terceiro, matemático, enxergava no jogo um bonito teorema prestes a ser resolvido.

A convivência no ambiente escolar possibilita diversas experiências que the acarretarão muitas noções básicas, que servirão como aprendizado para a vida como um conjunto de inovações. Sabemos que ao surgimento da matemática se deve à necessidade que o homem tem de buscar soluções para resolver problemas do dia-a-dia (FRANÇA, 2012). Por isso, acredita-se que o ensino da matemática, nos dias atuais, deve ser dinâmico. O ensino, por meio de jogos pedagógicos, 
deverá contribuir para desenvolver capacidades de lidar com situações novas, argumentar, sintetizar, planejar e organizar situações de aprendizagem (ROCKENBACH, 2010).

Soares (2016) entende que o xadrez é matemática pura, e que o jogo tem se mostrado imprescindível no ensino público, já que cada aluno tem a possibilidade de progredir de acordo com o seu próprio tempo e, mesmo durante a derrota, aprender que melhores competidores existem, mas que isso pode ser um incentivo se visto por um lado onde ambos ganham enquanto participam. A derrota é somente um contratempo para a formação de uma nova estratégia de jogo, para a melhora de habilidades, e para a criação do senso de humildade (FADEL, 2012).

\section{IMPLEMENTAÇÃO DO PROJETO}

O presente estudo buscou lecionar conteúdos da matemática utilizando estratégias do jogo de xadrez na sala de aula. Este estudo teve início na segunda quinzena do mês de agosto de 2014, até a primeira quinzena do mês de maio de 2019, realizado na Escola Municipal de Ensino Fundamental Sebastião Costa, localizada no Distrito de Itaici, no Município de Muniz Freire, ES, mas que já trouxe excelentes resultados.

O projeto realizado foi uma pesquisa de campo qualitativa, desenvolvido pelos professores das disciplinas de Matemática e Educação Física da EMEF Sebastião Costa. Todos os funcionários e alunos do $6^{\circ}$ ao $9^{\circ}$ ano participam deste projeto.

Foram programadas etapas para serem respeitadas - uma espécie de período de preparação, onde há uma ordem de atividades para que os participantes respeitem as regras e o cronograma. Primeiramente, foram apresentadas as regras do jogo: nomenclaturas das casas, o nome das peças, suas posições no tabuleiro e seus movimentos; depois, foram formadas as equipes, onde os docentes formaram duplas com os alunos, aprendendo e desenvolvendo juntos a destreza e estratégias do jogo, por meio de vídeo aulas, na prática, e/ou demais meios de pesquisa e; por fim, a etapa de reconhecimento, no qual os alunos que se sobressaíram melhor foram selecionados como monitores para prestar assistência ao professor de acordo com as dificuldades que possam surgir dos colegas de turma. 
Após o período de preparação, o projeto foi finalizado com um campeonato de jogo de xadrez, onde terá a participação de todos os alunos e funcionários da escola, tendo em vista que os alunos serão premiados com medalhas e troféus, como forma de incentivo. A fase inicial do projeto se deu após a aprovação da direção escolar e do setor pedagógico da escola. Em seguida, houve a realização de oficinas de xadrez, pré-estabelecidas em dias e horários convenientes à realização da mesma. Esta oficina esteve aberta para participação de todos alunos, funcionários e professores interessados na aprendizagem do jogo.

Durante o período do evento, os desempenhos em relação às notas dos alunos de matemática foram avaliados minuciosamente, no qual foi realizada uma análise quantitativa desses resultados. Entrevistas qualitativas também foram realizadas no final do evento, buscando informações mais precisas sobre o sentimento dos alunos em relação ao projeto.

\section{ANÁLISE E DISCUSSÃO DOS RESULTADOS}

Nesse novo contexto de escola, as propostas de trabalho nas aulas de matemática foram sendo modificadas, no qual foram inclusos os jogos de xadrez, que proporciona grandes experiências para os seus praticantes.

Durante o período do projeto, os alunos vivenciaram a oportunidade de construir novos conhecimentos matemáticos com o uso do jogo de xadrez, que foi utilizado como um instrumento de exemplificação e construção de conceitos referentes à matemática escolar. Um projeto de incentivo ao jogo está para acontecer com a permissão da direção da escola e, com a participação de docentes e dos alunos, ocorrerá um campeonato de xadrez e, paralelamente, uma pesquisa mais profunda sobre a potencialização do ensino aprendizagem diante deste evento será realizada.

No que tange à aplicabilidade do xadrez no ambiente escolar, destacou-se a comunicação efetiva entre educando e educadores. Na EMEF Sebastião Costa, a comunicação sobre o projeto foi diária, e o uso do xadrez como conteúdo pedagógico se tornou uma realidade na escola - e que deu muito certo. 
Um ponto bastante relevante foi de que o xadrez pedagógico teve, por meio de análises quantitativas, um potencial educativo maior para turmas com rendimento menores, isto é, serviu também como uma espécie de suporte pedagógico.

Todas as turmas tiveram melhoria em suas notas, mas as turmas com rendimento menor tiveram um destaque maior. Segundo depoimentos dos próprios alunos, o xadrez elevou a autoestima deles em pouco tempo, uma vez que o jogo trouxe situações imprevisíveis, instigando a autoconfiança e intensificando o raciocínio lógico para que fossem resolvidas.

Outro fator percebido foi de que houve uma menor evasão escolar. O motivo, ainda segundo os alunos, é que todas essas descobertas e evoluções auxiliaram de maneira significativa no comportamento dentro e fora da escola, ficando mais do que claro que a incitação da imaginação, do pensamento crítico e do uso de jogos tornaram o ambiente escolar agradável e propício para o ensino.

Percebeu-se, também, a diminuição da violência na escola - talvez pelo incentivo da inteiração no meio social. Além de proporcionar lazer, na EMEF Sebastião Costa, o xadrez é visto como uma construção de valores, habilidades e reconhecimento.

Até mesmo em uma visão mais generalizada do jogo, mesmo que indiretamente, os jogadores participantes calculam a todo momento a probabilidade de cada jogada dar certo, a antecipação de jogadas do oponente, as chances de eliminação de uma peça chave, aumentando assim as chances de vitória, entre outros fatores presentes no momento do jogo.

A matemática é o fator mais interessante do xadrez, e isso se dá pelo fato das próprias regras do jogo influenciarem nas decisões de ambos os jogadores a cada jogada. Caso uma jogada dê certo, o plano muda. Se der errado, muda. Se der muito certo, muda. Se der muito errado, muda. E, se não der em nada, também muda. Toda essa influência da matéria faz com que o tempo todo os jogadores atribuam planos e mais planos, em uma espécie de busca implacável pela solução enxadrística, onde se os problemas não forem solucionados, o jogo não acaba - a não ser que um lado desista da partida.

Evidenciou-se o quão íntimo o jogo é com a matemática, afinal, são vários os tipos de aprendizagem que podem ser assimilados à matéria ao jogo. Na aritmética, 
que é a parte da matemática que lida com os números e suas operações possíveis, o xadrez influi, por exemplo, no número de casas e no valor de peças.

$\mathrm{Na}$ álgebra, que adiciona variáveis e fórmulas nos cálculos, podemos analisar no xadrez o índice de chances de vitória de uma partida onde determinadas peças já foram eliminadas. A geometria, que lida com o estudo do espaço e das figuras ocupantes deste último, é visto no xadrez ao movimentarmos peças que se movem por diferentes casas de diferentes maneiras, como é o caso do cavalo, da rainha, torres, dos bispos, e até mesmo dos peões, ao realizarem uma captura.

Por meio dessa análise, foi possível entender que o jogo possui características cobradas no futuro destes alunos. O raciocínio lógico, a memória, o controle e a imaginação são só alguns dos exemplos da fonte rica de elementos que o jogo desenvolve nos alunos.

\section{CONSIDERAÇÕES FINAIS}

Este trabalho demonstrou que o xadrez é um importante instrumento pedagógico, que pode - e deve - ser utilizado pelo grupo pedagógico e pelos professores em sala de aula por ser de grande valia para os alunos.

Claro que houveram diversos desafios, sendo os principais deles a carência de profissionais preparados e engajados para a aplicação do projeto, e a dificuldade no convencimento de que o xadrez tivesse um enfoque pedagógico, e não meramente esportivo.

Esses desafios foram vencidos e, aos poucos, se tornaram um aprendizado para todos os participantes, que puderam ver de perto o desenvolvimento contínuo dos alunos das séries iniciais da EMEF Sebastião Costa. Estes vivenciaram o importante papel do xadrez no ambiente escolar: um jogo relativamente barato, durável, e que recuperou alunos com problemas de notas e comportamento, elevando sua moral e estima; que expandiu com certa facilidade o número de participantes, reconhecendo os esforços daqueles que mais se esforçaram; e que removeu o enfoque onde há somente vencedores, no qual todos os participantes eram aceitos e bem recebidos, criando uma janela de aprendizagem universal. 
Busca-se a superação como objetivo. E o objetivo foi cumprido. O xadrez, de fato, foi um grande incentivador e fornecedor de situações. Essas situações são matematicamente resolvidas a cada instante da partida, de maneira a formar um grande quebra-cabeças, no qual os alunos solucionam e criam novas perspectivas a todo momento.

Como plano futuro, o projeto deverá continuar, e alunos e professores da EMEF Sebastião Costa estarão capacitados para ajudar na implantação do xadrez agora em toda a comunidade, e novos projetos como este poderão ser readaptados e realizados de tempos em tempos.

\section{BIBLIOGRAFIAS}

ANGÉLICO, L. P; PORFÍRIO, L. C. O jogo de xadrez modifica a escola: Por que se deve aprender xadrez e tê-lo como eixo integrador no currículo escolar? Revista Eletrônica da Faculdade Semar/Unicastelo. Volume: 1. Número: 1. Edição Outubro e janeiro de 2010.

FADEL, J. G. R. $O$ xadrez como atividade complementar na escola: uma possibilidade de utilização do jogo como instrumento pedagógico. Trabalho apresentado à Secretaria de Estado da Educação do Estado do Paraná/Superintendência de Educação/Diretoria de Políticas e Programas Educacionais/Programa de Desenvolvimento Educacional, 2012. Disponível em: <http://www.diaadiaeducacao.pr.gov.br/portals/pde/arquivos/503-4.pdf>. Acesso em: 05, ago 2016.

FRANÇA, C. S. O xadrez como ferramenta pedagógica para as aulas de Educação Física Escolar. Trabalho de Conclusão de Curso - Universidade Estadual da Paraíba, Centro de Ciências Biológicas e da Saúde. Campina Grande, PB, 2012. Disponível em: <http://dspace.bc.uepb.edu.br/jspui/bitstream/123456789/895/1/PDF\%20-

\%20Cristiano\%20de\%20Sousa\%20Fran\%C3\%A7a.pdf>. Acesso em: 05, ago 2016.

GIACHINI, F. A. A influência do xadrez no desenvolvimento da capacidade de concentração em alunos da $6^{2}$ série do ensino fundamental. Unisep - União de Ensino do Sudoeste do Paraná. Dois Vizinhos, PR. Brasil 2011.

ROCKENBACH, R. R. B. O xadrez escolar e sua relação com a satisfação familiar. $1^{\text {a }}$ Ed, Dois Vizinhos: Carikol, 2010.

SILVA, R. R. V. Práticas pedagógicas no ensino aprendizagem do jogo de xadrez em escolas. Dissertação de Mestrado. Faculdade de Ed. Física da Universidade de Montes Claros, MG. Motriz, Rio Claro, v.16, n.3, p.809-809, jul./set, 2009.

SOARES, C. 0 uso do xadrez como mediador na educação matemática: uma abordagem lúdica no ensino de matemática. Novas Edições Acadêmicos, 2016. 